\title{
Extremely Short Optical Pulses in a Photonic Crystal Made of Carbon Nanotubes
}

\author{
Yu.V. Dvuzhilova, I.S. Dvuzhilov*, M.B. Belonenko \\ Volgograd State University, 100, University Ave., 400062 Volgograd, Russia
}

(Received 17 July 2020; revised manuscript received 15 February 2021; published online 25 February 2021)

\begin{abstract}
We have considered the problem of the evolution of two-dimensional few-cycle optical pulses inside a photonic crystal, which has a spatially modeled refractive index, from oriented carbon nanotubes. Based on Maxwell's equations, using the Coulomb calibration, an effective equation for the vector potential of the electric field of an extremely short pulse was written. Numerical simulation of the pulse dynamics in a medium with a spatially variable refractive index was carried out using a numerical scheme of the "cross" type. It was shown that the pulse propagation is stable in the considered medium. The pulse energy remains localized in a limited region of space, but dispersive spreading of the pulse shape takes place. The dynamics of the pulse was also considered as a function of the parameters of the photonic crystal (modulation depth and period of the refractive index); it showed that it is possible to control the speed of a group packet of a few-cycle optical pulse. The calculations were carried out at times up to $10 \mathrm{ps}$, which plays an important role in theoretical and applied research.
\end{abstract}

Keywords: Extremely short optical pulses, Photonic crystal, Carbon nanotube.

\section{INTRODUCTION}

Among the popular phenomena in nonlinear and coherent optics, the study of the dynamics of pulses containing a small number of periods of electromagnetic field oscillations or the so-called extremely short optical pulses is currently of great interest. Such pulses are also called light bullets [1]. The light bullet is generally viewed as a limited spatial two- or threedimensional pulse, the total energy of the electromagnetic field of which is localized in a small spatial region of a medium. In other words, light bullets can be understood as well-known electromagnetic solitons if the medium is two- or three-dimensional [2]. One of the main characteristics of extremely short optical pulses is the impossibility of separating the shape of an electromagnetic pulse into an envelope and a bearing part which may be of interest to researchers in many respects. That is why in this case we cannot use the multiscale expansion method for solving Maxwell's equations. There is a need to solve Maxwell's equations without discarding any derivatives [3]. We have to point to the fact that if the medium can be characterized by spatial dispersion, then nonlinearity must be taken into account even in the one-dimensional case.

In this paper, we have considered photonic crystals, by which we mean a medium with a spatially periodic refractive index and which have a photonic band gap. Thus, a photonic crystal can be considered as an optical filter that is capable of transmitting photons with a certain frequency $[4,5]$.

Spatial inhomogeneity inside the photonic crystal provides us an ideal nonlinear medium for the study and propagation of electromagnetic solitons, extremely short optical pulses or light bullets [6].

Carbon nanotubes (CNTs) are the most convenient material for a medium of photonic crystals, in which extremely short optical pulses or light bullets can propagate. This is not surprising, because CNTs have unique nonlinear physical properties in the optical range, which makes them a very promising material for the formation of a nonlinear medium with a variable refractive index, for studying the propagation of threedimensional extremely short optical pulses [7, 8].

One of the most interesting applications of photonic structures with a band gap is the possibility of creating a new type of optical fibers based on such media, the main merit of which is the possibility of edgewise waveguide bending without light leakage [9].

All of the above, in combination with the importance of practical application of two-dimensional few-cycle optical pulses, served as an incentive for writing this paper.

\section{THE BASIC EQUATIONS}

In this paper, we have studied $\pi$-electrons of CNTs using the tight-bond approximation. The law of dispersion for semiconductor CNTs of zig-zag type can be written as [10]:

$$
E(\mathbf{p})= \pm \gamma \sqrt{1+4 \cos (a p) \cos (\pi s / m)+4 \cos ^{2}(\pi s / m)}
$$

where $\gamma=2.7 \mathrm{eV}, a=3 b / 2 \hbar, b=0.142 \mathrm{~nm}$ is the distance between neighboring carbon atoms, and the quasimomentum $\mathbf{p}$ is given as $\left(p_{z}, s\right), s=1,2, \ldots m$.

The electromagnetic field of a two-dimensional fewcycle optical pulse inside a CNT photonic crystal is described using the Maxwell's equations with Coulomb calibration. The vector-potential has one $z$-component, which depends on the spatial coordinate and time

$$
\frac{\partial^{2} \mathbf{A}}{\partial x^{2}}+\frac{\partial^{2} \mathbf{A}}{\partial y^{2}}-\frac{n^{2}(x, y)}{c^{2}} \frac{\partial^{2} \mathbf{A}}{\partial t^{2}}+\frac{4 \pi}{c} \mathbf{j}=0
$$

where $n(x, y)$ is the spatially variable refractive index, i.e. a photonic crystal with modulation of the refractive index, $j$ is the electric current that arises due to the

\footnotetext{
*dvuzhilov.ilya@volsu.ru
} 
interaction of electrons located in the CNT conduction band with the electromagnetic field of extremely short optical pulses.

As the main approximations and assumptions, we have used:

1) the electric field of the surface, on which the CNTs are located, is not taken into account;

2) band-to-band transitions are not taken into account, because this reduces the boundaries of the pulse frequency, which is in the near IR range;

3) we have used the approximation of a continuous medium, thus, it is assumed that the emerging current is dispersed throughout the volume.

The third assumption is suitable because the spatial region, in which extremely short optical pulses are localized, is much larger than the size of CNTs and the distance between them.

The distance at which there are strong changes in the value of the refractive index for a photonic crystal is even greater, therefore this fact does not have a significant effect.

We have described the evolution of extremely short optical pulses at times of about 10 fs using the collisionless kinetic Boltzmann equation [11]

$$
\frac{\partial f}{\partial t}-\frac{q}{c} \frac{\partial \mathbf{A}_{z}}{\partial t} \frac{\partial f}{\partial p}=0
$$

where $f=f\left(p_{s}, s, t\right)$ is the distribution function, which depends on the vector-potential $\mathbf{A}$, and as a consequence on coordinate. At the initial time, this function coincides with the equilibrium Fermi distribution function $F_{0}$

$$
F_{0}=\frac{1}{1+\exp \left\{E(\mathbf{p}) / k_{b} T\right\}}
$$

where $T$ is the temperature and $k_{b}$ is the Boltzmann constant.

The current density $\mathbf{j}=\left(0,0, j_{z}\right)$ can be written as

$$
j_{z}=\frac{q}{\pi \hbar} \sum_{s} \int d p_{z} v_{z} f
$$

where $v_{z}=\partial E(\boldsymbol{p}) / \partial p_{z}$ is the group velocity of electrons.

Solving equation (3) by using the methods of characteristics, we can come to

$$
j_{z}=\frac{q}{\pi \hbar} \sum_{s} \int_{-q_{0}}^{q_{0}} d p_{z} v_{z}\left[p-\frac{q}{c} A_{z}(t)\right] F_{0}(\mathbf{p}),
$$

The integration in equation (5) is carried out over the first Brillouin zone, $q_{0}=2 \pi \hbar / 3 b$.

Considering the dispersion law, the group velocity can be transformed into a Fourier series

$$
v_{z}(s, x)=\sum_{m} a_{m s} \sin (m x),
$$

where $a_{m s}=\frac{1}{\pi} \int_{-\pi}^{\pi} v_{z}(s, x) \sin (m x) d x$ are the coefficients of expansion which decrease with increasing $m$.

Finally, an effective equation can be represented as

$$
\begin{gathered}
\frac{\partial^{2} A_{z}}{\partial x^{2}}+\frac{\partial^{2} A_{z}}{\partial y^{2}}-\frac{n^{2}(x, y)}{c^{2}} \frac{\partial^{2} A_{z}}{\partial t^{2}}+\frac{q}{\pi \hbar} \sum_{m} c_{m} \sin \left(\frac{m a q}{c} A_{z}(t)\right)=0 \\
c_{m}=\sum_{m} a_{m s} b_{m s}, \quad b_{m s}=\int_{-q_{0}}^{q_{0}} d p_{z} \cos \left(m a p_{z}\right) F_{0}(\mathbf{p}) .
\end{gathered}
$$

Since, as a result of the numerical solution, the values of the coefficients $c_{m}$ decrease, we can restrict ourselves to the first few terms of expansion (for our calculations, we have used the first 10 terms).

\section{RESULTS AND DISCUSSION}

Equation (6) has been solved using numerical methods, namely, the difference approximation method. The difference scheme "cross" has been used. To determine the time and coordinate grid we have used the Courant-Friedrichs-Lewy condition. The accuracy of the solution is about $99.99 \%$. The initial condition of the potential-vector can be written as:

$$
\begin{aligned}
& A_{t=0}=A_{0} \exp \left\{-\frac{x^{2}}{\gamma^{2}}\right\} \exp \left\{-\left(y-y_{c}\right)^{2} / \beta^{2}\right\} \\
& \left.\frac{d A}{d t}\right|_{t=0}=\frac{2 v x}{\gamma^{2}} A_{0} \exp \left\{-\frac{x^{2}}{\gamma^{2}}\right\} \exp \left\{-\left(y-y_{c}\right)^{2} / \beta^{2}\right\}
\end{aligned}
$$

where $y_{c}$ is the initial position of the pulse with respect to the ordinate axis, $\beta$ and $\gamma$ are the parameters of the pulse width along the $y$ and $z$ axes respectively, $v$ is the initial velocity of the pulse.

The medium refraction index can be written as

$$
n(x)=n 0(1+\alpha \cos (2 \pi x / \chi))
$$

where $a$ is the modulation depth of the medium refraction index and $x$ is the lattice constant of the photonic crystal.

The results of numerical modeling have shown that (Fig. 1) the solution of the equation for two-dimensional extremely short optical pulses in a photonic crystal of CNTs over time stays limited in a small spatial region, which means that the balance between the dispersion and nonlinearity of the CNT medium allows such a pulse to propagate stably.

Fig. 1 has shown that a lot of peaks form in the transverse structure of the pulse. It has happened due to the synchronizing action of the dispersion effects of spreading and nonlinearity of the medium, but through it all, this pulse remains localized in such a medium.

As can be seen from Fig. 2, the index of the modulation depth does not affect the shape of the pulse much. The amplitude of the pulse almost retains its value. Extremely short optical pulses stay concentrated in a limited area of space. Only in the transverse structure, you can see small changes.

The next result is about the dependence of the shape and velocity of extremely short optical pulses on the lattice constant of a photonic crystal $x$. As we might expect, extremely short optical pulses propagate faster with an increase in the lattice constant. Obviously, if the lattice constant is infinite, then the pulse will propagate with maximum velocity due to the absence of interference processes. This fact has been confirmed by numerical calculations. Also we have noted the distortion of the pulses shape. 

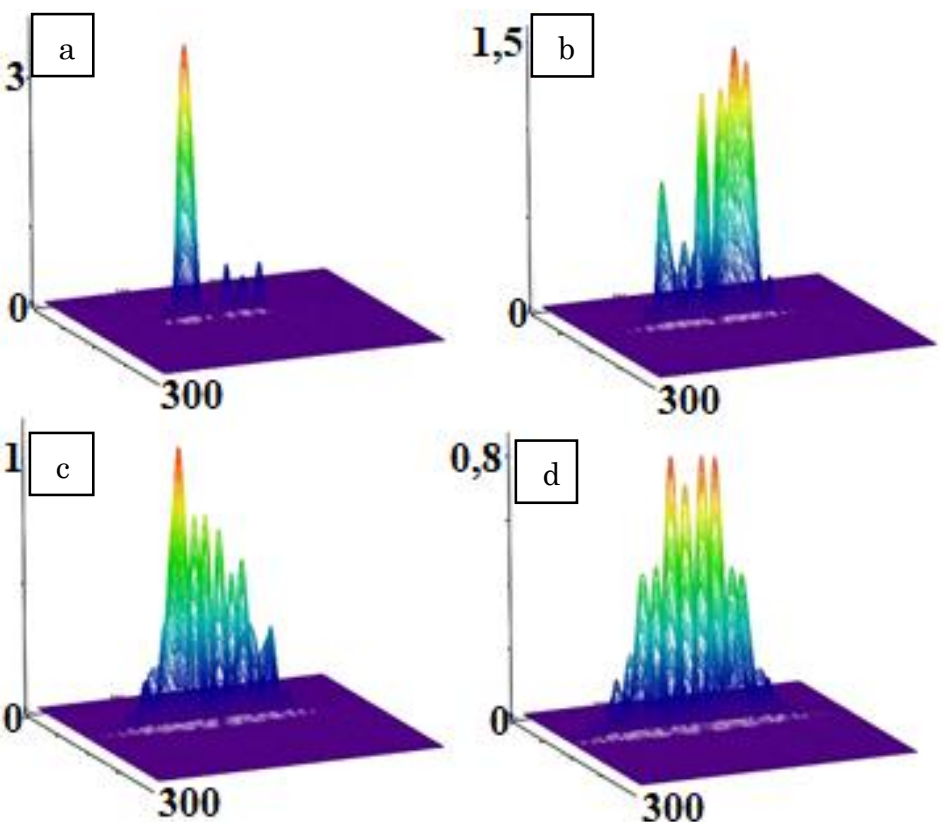

Fig. 1 - The evolution of the two-dimensional extremely short optical pulses inside the photonic crystal made of CNTs with a period of $2.5 \mu \mathrm{m}$ at different moments of time ( $T=2 \mathrm{ps})$ : a) $T, \mathrm{~b}$ ) $2 T$, c) $3 T, \mathrm{~d}) 4 T$. The $x$ and $y$ values are relative values of coordinates and electrical field $\left(10^{8} \mathrm{~V} / \mathrm{m}\right)$
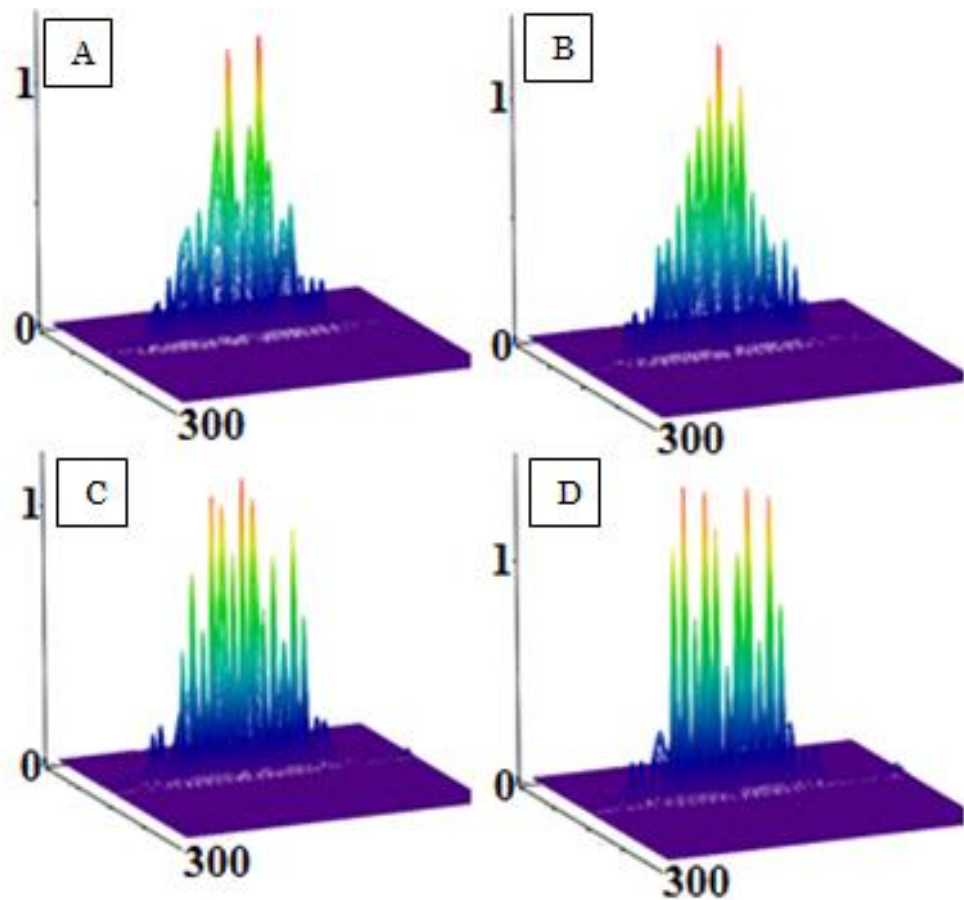

Fig. 2 - The evolution of the two-dimensional extremely short optical pulses inside the photonic crystal made of CNTs with a period of $2.5 \mu \mathrm{m}$ with the different index of the modulation depth $a$ at the moment of time $T=8$ ps: a) $a=0.3, b) a=0.45$, c) $a=0.6$, d) $a=0.75$. Values of the $x$ - and the $y$-axis are relative values of coordinates and electrical field $\left(10^{8} \mathrm{~V} / \mathrm{m}\right)$

\section{CONCLUSIONS}

So, based on the results of this paper, we can make the conclusion: in a photonic crystal with a spatially variable refractive index of CNTs, a stable propagation of twodimensional extremely short optical pulses is possible. The dependences of the propagation of two-dimensional extremely short optical pulses on the lattice constant and modulation depth have been also determined. When these parameters change, the propagation velocity and the shape of the pulse also change. Thus, changing the parameters of the medium, we can control the properties of the pulse, which is important for practical applications.

As said above, these results can be used to construct waveguides based on photonic crystals without energy loss on the bends of the material. 


\section{ACKNOWLEDGEMENTS}

The authors thank the Ministry of Science and Higher Education of the Russian Federation for the numerical modeling and parallel computations support under the government task (0633-2020-0003).

\title{
REFERENCES
}

1. G. Fibich, B. Ilan, Opt. Let. 29, 887 (2004).

2. R.K. Dodd, J.C. Eilbeck, J.D. Gibbon, H.C. Morris, Solitons and Nonlinear Wave Equations (London: Academic Press: 1982).

3. M.V. Gudkov, N.G. Ryvkina, V.P. Melnikov, DOPC 466, 1 (2016)

A.Ya. Gorenberg,

4. A. Mekis, J.C. Chen, I. Kurland, S. Fan, P.R. Villeneuve, J.D. Joannopoulos, Phys. Rev. Lett. 77, 3787 (1996).

5. M. Tokushima, H. Kosaka, A. Tomita, H. Yamada, Appl. Phys. Lett. 76, 952 (2000)

6. S.V. Sazonov, N.V. Ustinov, Phys. Rev. A. 98, 063803 (2018).

7. A.V. Zhukov, R. Bouffanais, M.B. Belonenko, I.S. Dvuzhilov, Yu.V. Nevzorova, Appl. Phys. B 123, 196

(2017).

8. M.B. Belonenko, I.S. Dvuzhilov, Yu.V. Nevzorova, E.N. Galkina, Nanosyst. Phys. Chem. Math. 8 No 4, 435 (2017).

9. S.V. Sazonov, A.A. Kalinovich, B.D. Sobolev, M.V. Komissarova, I.G. Zakharova, Izvestiya RAN. Seriya fizicheskaya, 83 (2019).

10. Nanotechnology Research Directions: Vision for Nanotechnology in the Next Decade (Eds. by M.C. Roco, R.S. Williams, P. Alivisatos) (Moscow: Mir: 2002) [In Russian].

11. P.J.F. Harris, Carbon Nanotubes and Related Structures: New Materials for the 21st Century (Cambridge: Cambridge University Press: 2009).

\section{Двовимірні надзвичайно короткі оптичні імпульси в фотонному кристалі з вуглецевих нанотрубок}

\author{
Ю.В. Двужилова, И.С. Двужилов, М.Б. Белоненко
}

Волгоградський державний університет, пр-т Університетський, 100, 400062 Волгоград, Росія

Була розглянута проблема еволюції двовимірних коротких оптичних імпульсів всередині фотон ного кристала, який має просторово модульований показник заломлення, з оріентованих вуглецевих нанотрубок. На підставі рівнянь Максвелла, з використанням калібрування Кулона, написано ефективне рівняння для вектор-потенціалу електричного поля надкороткого імпульсу. Було проведено чисельне моделювання динаміки імпульсу в середовищі з просторово змінним показником заломлення, з використанням чисельної схеми типу «хрест». Показано, що поширення імпульсу стабільне в розглянутому середовищі. Енергія імпульсу залишаеться локалізованою в обмеженій області простору, однак має місце дисперсійне розпливання форми імпульсу. Також була розглянута динаміка імпульсу в залежності від параметрів фотонного кристала (глибина модуляції і період показника заломлення); вона показала, що існуе можливість контролювати швидкість групового пакету гранично короткого імпульсу. Розрахунки проводилися для часу до 10 пс, що грає важливу роль в теоретичних і прикладних дослідженнях.

Ключові слова: Гранично короткі оптичні імпульси, Фотонний кристал, Вуглецеві нанотрубки. 